Article

\title{
Resource Recovery of Waste Nd-Fe-B Scrap: Effective Separation of Fe as High-Purity Hematite Nanoparticles
}

\author{
Suiyi Zhu ${ }^{1}$, Ting Su ${ }^{1}$, Yu Chen ${ }^{2}$, Zhan $Q u^{1}{ }^{1}$, Xue Lin ${ }^{1}$, Ying Lu ${ }^{1, *}$ and Mingxin Huo ${ }^{1}$ \\ 1 Science and Technology Innovation Centre for Municipal Wastewater Treatment and Water Quality \\ Protection, Northeast Normal University, Changchun 130117, China; zhusy812@nenu.edu.cn (S.Z.); \\ sut001@nenu.edu.cn (T.S.); quz206@nenu.edu.cn (Z.Q.); 13196049899@163.com (X.L.); \\ huomx097@nenu.edu.cn (M.H.) \\ 2 Design Department, Jilin Institute of Forestry Survey and Design, Changchun 130022, China; \\ 18404314446@163.com \\ * Correspondence: luy332@nenu.edu.cn; Tel.: +86-0431-89165610
}

Received: 13 February 2020; Accepted: 10 March 2020; Published: 26 March 2020

\begin{abstract}
Recycling rare-earth elements from Nd magnet scrap (Nd-Fe-B scrap) is a highly economical process; however, its efficiency is low due to large portions of Fe impurity. In this study, the effective separation of Fe impurity from scrap was performed through an integrated nitric acid dissolution and hydrothermal route with the addition of fructose. Results showed that more than $99 \%$ of the scrap was dissolved in nitric acid, and after three dilutions that the Nd, Pr, Dy and Fe concentrations in the diluted acid were 9.01, 2.11, 0.37 and $10.53 \mathrm{~g} / \mathrm{L}$, respectively. After the acid was hydrothermally treated in the absence of fructose, only $81.8 \%$ Fe was removed as irregular hematite aggregates, whilst more than $98 \%$ rare-earth elements were retained. By adding fructose at an $\mathrm{M}_{\text {fructose }} / \mathrm{M}_{\text {nitrate }}$ ratio of $0.2,99.94 \%$ Fe was precipitated as hematite nanoparticles, and the loss of rare-earth elements was $<2 \%$. In the treated acid, the residual Fe was $6.3 \mathrm{mg} / \mathrm{L}$, whilst $\mathrm{Nd}$, Pr and Dy were 8.84, 2.07 and $0.36 \mathrm{~g} / \mathrm{L}$, respectively. Such composition was conducive for further recycling of high-purity rare-earth products with low Fe impurity. The generated hematite nanoparticles contained $67.92 \% \mathrm{Fe}$ with a rare-earth element content of $<1 \%$. This value meets the general standard for commercial hematite active pharmaceutical ingredients. In this manner, a green process was developed for separating Fe from $\mathrm{Nd}-\mathrm{Fe}-\mathrm{B}$ scrap without producing secondary waste.
\end{abstract}

Keywords: Nd-Fe-B scrap; hydrothermal treatment; rare-earth elements; recycling; hematite

\section{Introduction}

$\mathrm{Nd}$ magnet scrap (Nd-Fe-B scrap) is a common material in the collection of magnetic products in the permanent magnet industry [1]. This scrap is composed of approximately $30 \%$ rare-earth elements and $50-70 \% \mathrm{Fe}$ impurity [2]. Given that such rare-earth elements are indispensable to improving the thermal and oxidation-corrosion resistances of advanced materials in advanced manufacturing and energy industries [3], recycling rare-earth elements from scrap is a highly economical and reliable process.

Numerous approaches for recycling rare-earth elements from scrap have been developed, including selective precipitation [4], solvent extraction [5-9] and cationic exchange [1]. Amongst these approaches, the first step in recycling rare-earth elements is dissolving scrap in strong acids, including sulphuric, nitric and hydrochloric acids $[5,6,10]$. After dissolution, rare-earth elements are recycled in two ways. The first method is precipitating ferric Fe by adjusting the rare-earth element-bearing acid to above pH 3 [4]. For example, Önal et al. [4] dissolved scrap in sulphuric acid and found that ferrous Fe in 
the acid was oxidised to ferric Fe by adding $\mathrm{MnO}_{2}$ and then precipitated as Fe oxyhydroxide when the acid was adjusted to $\mathrm{pH} 3$ using $\mathrm{Ca}(\mathrm{OH})_{2}$. In this process, approximately $23 \%$ of the rare-earth elements were lost. Fe was hydrolysed into Fe oxyhydroxide, which has plenty of surface hydroxyl groups for rare-earth element coordination [11,12]. Thus, the coprecipitation of Fe and the rare-earth elements results in the loss of such elements. The other approach is extracting rare-earth elements from acid through an extraction solvent, such as sec-octylphenoxy acetic acid [7], $\mathrm{NaD}_{2}$ EHPA [8] and tributyl phosphate $[9,13]$. However, Fe also reacts with the extraction solvent, and it accumulates with the repeated use of the solvent. This condition increases the cost of rare-earth element extraction and complicates the purification process [14]. Therefore, Fe impurity is undesirable and should be effectively removed for the high-purity recycling of rare-earth elements.

Fe was hydrothermally hydrolysed to generate well-crystallised hematite at acid $\mathrm{pH}<3[5,15,16]$. Wieczorek-Ciurowa et al. [15] found that anhydrous hematite appeared in the decomposition product of $\mathrm{Fe}\left(\mathrm{NO}_{3}\right)_{3} \cdot 9 \mathrm{H}_{2} \mathrm{O}$, with $\mathrm{Fe}(\mathrm{OH})\left(\mathrm{NO}_{3}\right)_{2}$ and $\mathrm{Fe}(\mathrm{OH})_{2} \mathrm{NO}_{3}$ as intermediates, after heating at $105^{\circ} \mathrm{C}$ for 4 days. The number of surface hydroxyl groups decreased with hematite generation compared with that of Fe oxyhydroxide [11] and, thus, residual cationic ions were highly concentrated in the acid [5,17-19]. Yang et al. dissolved sphalerite in strong sulphuric acid, and then hydrothermally treated the acid at $190{ }^{\circ} \mathrm{C}$ for $3 \mathrm{~h} \mathrm{[5]}$. They found that $95.3 \% \mathrm{Fe}$ in Fe/Zn-bearing sulphuric acid was hydrolysed in the forms of hematite, goethite and jarosite, whilst Zn concentration remained nearly unchanged. During Fe hydrolysis, $\mathrm{H}^{+}$was generated and gradually accumulated in the acid, in which Fe hydrolysis was in equilibrium. Thus, the Fe residual was at a high concentration of nearly $2.5 \mathrm{~g} / \mathrm{L}$ [5], which should be further removed before rare-earth element recycling.

Given that a high amount of rare-earth element residual was found in hydrothermally treated acid, a one-step hydrothermal route with fructose as auxiliary reagent was developed for effectively separating Fe from the acid solution of scrap. By adding fructose, portions of $\mathrm{H}^{+}$was consumed in the redox reaction between fructose and nitrite, which promoted the hydrolysis and precipitation of residual $\mathrm{Fe}^{3+}$. Unlike the $2.5 \mathrm{~g} / \mathrm{L} \mathrm{Fe}$ that was residual in the conventional method, less than $10 \mathrm{mg} / \mathrm{L} \mathrm{Fe}$ was kept with the new hydrothermal route, while only less than $2 \%$ rare-earth elements were lost.

\section{Materials and Methods}

\subsection{Scrap Dissolution}

The scrap sample was collected from the cutting workplace of SanHe Ltd. (Jilin, China), dried at $105{ }^{\circ} \mathrm{C}$ for $3 \mathrm{~h}$, ground and sifted with a sieve $(1 \mathrm{~mm}$ mesh). The grey scrap was subjected to wet chemical analysis following the method of Sandroni and Smith [20]. The major elements of the sludge based on the dry weight was $45.5 \% \mathrm{Fe}, 38.9 \% \mathrm{Nd}, 9.1 \% \mathrm{Pr}$ and $1.6 \% \mathrm{Dy}$, indicating that rare-earth elements and Fe predominated the scrap. The scrap was dissolved as follows: $5 \mathrm{~g}$ of scrap was dispersed in $100 \mathrm{~mL} 27 \%$ nitric acid, and then the acid was heated at $60{ }^{\circ} \mathrm{C}$ under constant stirring at $250 \mathrm{rpm}$. After $30 \mathrm{~min}$, the acid bubbled to emit a yellowish smoke due to the redox reaction between the nitrate and Fe/rare-earth metals during the scrap's dissolution. In the nitric acid solution, nitrate had a high redox potential $E_{\mathrm{NO}_{3}^{-}} / \mathrm{NO}$ of $2.23 \mathrm{~V}$ [3] to oxidize the mental in the scrap to generate $\mathrm{Fe}^{3+}$ and trivalent rare-earth elements [4]. Subsequently, a yellowish suspension was generated after $6 \mathrm{~h}$ and its volume was approximately $74 \mathrm{~mL}$, indicating that approximately $26 \%$ of the solution evaporated. The suspension was centrifugal separation at $5500 \mathrm{rpm}$ for $5 \mathrm{~min}$, and then the residual solid was collected and dried at $102{ }^{\circ} \mathrm{C}$ for $4 \mathrm{~h}$. The residual undissolved solid was approximately $0.08 \mathrm{~g}$, suggesting that more than $99 \%$ of the scrap was dissolved. After centrifugation, the supernatant was collected and characterised via ion chromatography (IC, 881, Metrohm, Herisau, Switzerland). The results indicated that nitrate concentration was $266.1 \mathrm{~g} / \mathrm{L}$, demonstrating that approximately $25 \%$ nitrate was exhausted during the scrap's dissolution. To prevent the vessel from exploding in the subsequent hydrometallurgical experiment, the supernatant was diluted three times and characterised via inductively coupled plasma atomic emission spectroscopy (ICP-OES, Profile, Leeman, Hudson, 
$\mathrm{NH}$, USA). The major elements were determined to be $88.7 \mathrm{~g} / \mathrm{L} \mathrm{NO}_{3}{ }^{-}, 10.53 \mathrm{~g} / \mathrm{L} \mathrm{Fe}, 9.01 \mathrm{~g} / \mathrm{L} \mathrm{Nd}, 2.11 \mathrm{~g} / \mathrm{L}$ Pr and $0.37 \mathrm{~g} / \mathrm{L}$ Dy.

\subsection{Precipitation of Fe Impurity}

Fe impurity in the acid was separated via a one-step hydrothermal route. Firstly, $20 \mathrm{~mL}$ of diluted acid was poured into a $50 \mathrm{~mL}$ Teflon ${ }^{\mathrm{TM}}$ vessel, followed by the addition of fructose at an $\mathrm{M}_{\text {fructose }} / \mathrm{M}_{\text {nitrate }}$ molar ratio (hereafter referred to as "molar ratio") of 0.1 . Secondly, the vessel was placed in a dry oven (DHG-9030A, Shanghai-Yiheng, China) and heated at $160^{\circ} \mathrm{C}$ for $6 \mathrm{~h}$. Thirdly, the deposit was collected and freeze-dried at $-80^{\circ} \mathrm{C}$ for $24 \mathrm{~h}$. Control experiments were performed by varying the molar ratio from 0 to $0.1,0.2$ and 0.5. Optimal Fe removal occurred at a molar ratio of 0.2; thus, the time course of the removal rate of Fe was also investigated. Each experiment was repeated three times, and the standard deviation was calculated as the error bar.

\subsection{Characterisation}

To analyse the Fe precipitate, the obtained deposits were characterised via scanning electron microscopy (SEM, NanoSEM 450, FEI Co., Hillsboro, OR, USA) and X-ray diffractometry system (XRD, RAPID-S, Rigaku, Tokyo, Japan). Acidity before and after hydrothermal treatment was recorded using a $\mathrm{pH}$ meter (E-201-C, LeiCi, Shanghai, China) and organic matter in the acid solution was determined using a total organic carbon analyser (TOC, TOC-5000A, Shimadzu, Kyoto, Japan).

\section{Results and Discussion}

\subsection{Fructose Dosage Optimisation}

Fe impurity was efficiently separated from the rare-earth element-bearing acid, as shown in Figure 1. Without fructose, only $81.8 \%$ of the total Fe was removed, and the loss of $\mathrm{Nd}$, Pr and Dy were $1.4 \%, 1.3 \%$ and $1.1 \%$, respectively. With fructose, Fe removal reached $97 \%$ at a molar ratio of 0.1 , nearly $100 \%$ at a molar ratio of 0.2 and only $72.5 \%$ at a molar ratio of 0.5 (Figure $1 \mathrm{a}$ ). Accordingly, the loss of $\mathrm{Nd}, \mathrm{Pr}$ and Dy increased slightly to $1.5 \%, 1.8 \%$ and $1.5 \%$ at a 0.1 molar ratio and $1.7 \%, 1.9 \%$ and $1.6 \%$ at a 0.2 molar ratio, but dramatically to $21.9 \%, 27.5 \%$ and $29.5 \%$ at the 0.5 molar ratio (Figure $1 b$ ), respectively. This outcome indicated that fructose was overdosed at a molar ratio of 0.5 . Thus, the molar ratio of 0.2 was optimal. Under this condition, nearly $100 \%$ Fe was removed and only $6.3 \mathrm{mg} / \mathrm{L}$ Fe was retained, but rare-earth element loss was below $2 \%$.
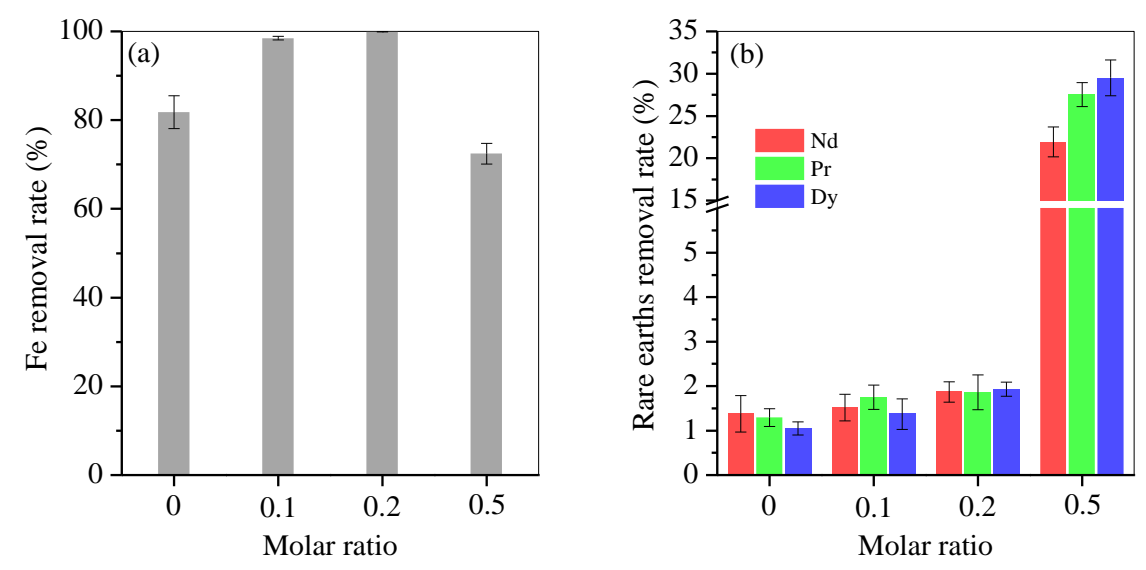

Figure 1. Removal rate of (a) Fe and (b) rare-earth elements by varying the $\mathrm{M}_{\text {fructose }} / \mathrm{M}_{\text {nitrate }}$ molar ratio from 0 to $0.1,0.2$ and 0.5 .

When fructose was absent, the removed Fe precipitated in the form of irregular hematite aggregates (Figures 2a and 3a). Fructose was helpful in removing Fe. By adding fructose at a molar ratio of 
0.1, Fe precipitated as hematite nanoparticles (Figures $2 \mathrm{~b}$ and $3 \mathrm{~b}$ ) with a diameter of $400 \mathrm{~nm}$. The diameter of the hematite nanoparticles was further decreased to $100 \mathrm{~nm}$ with an increase in molar ratio to 0.2 (Figures $2 \mathrm{c}$ and $3 \mathrm{c}$ ). When the molar ratio was 0.5 , the obtained deposit presented three sharp peaks at $2 \theta=18.5^{\circ}, 18.9^{\circ}$ and $22.7^{\circ}$ (Figure $2 \mathrm{~d}$ ), which belonged to humboldtine, and a broad peak at $2 \theta=22.2^{\circ}$, which was affiliated with the $C$ sphere from the polymerisation of overdosed fructose [21]. Accordingly, fine spherical particles with diameters of $2-5 \mu \mathrm{m}$ were observed (Figure $3 \mathrm{~d}$ ). This condition demonstrated that overdosed fructose was involved in the formation of $\mathrm{C}$ spheres.

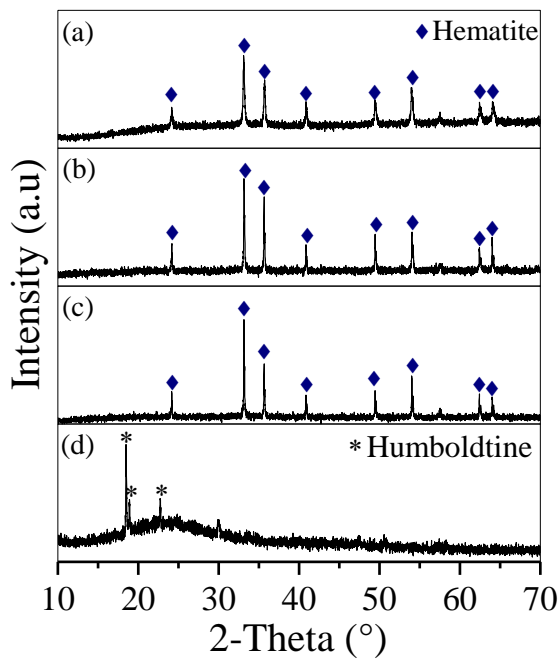

Figure 2. XRD curves of the deposit generated at $\mathrm{M}_{\text {fructose }} / \mathrm{M}_{\text {nitrate }}$ ratios of (a) 0, (b) 0.1, (c) 0.2 and (d) 0.5 .

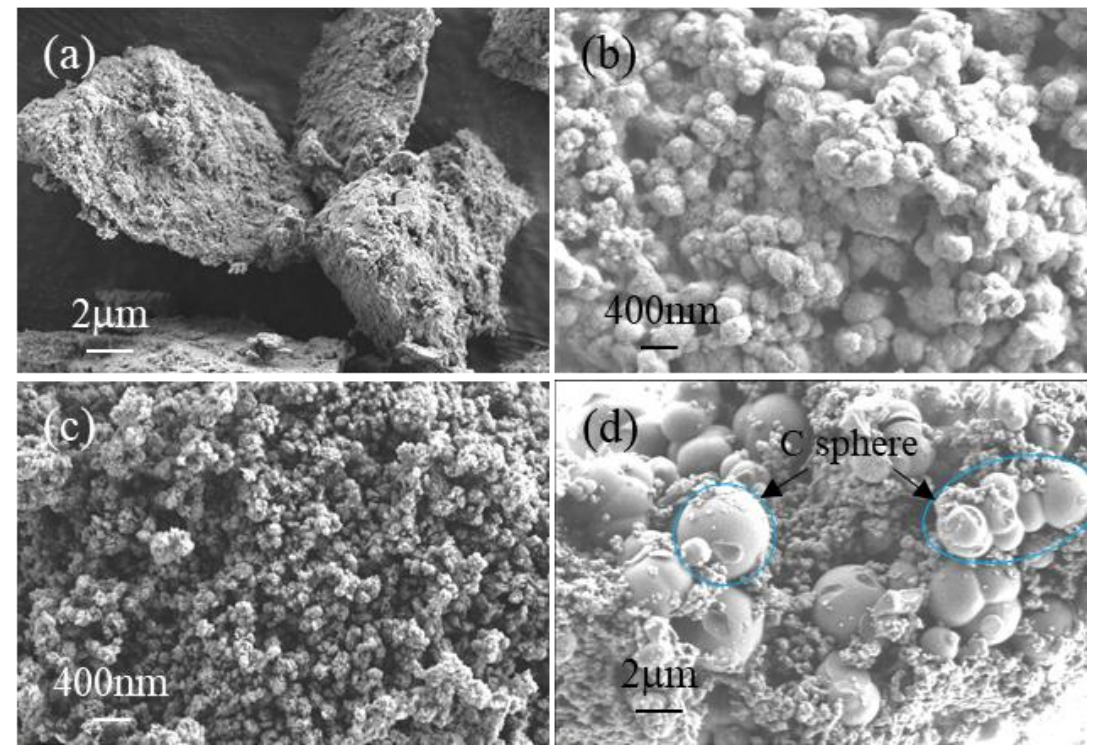

Figure 3. SEM images of the deposit generated at $\mathrm{M}_{\text {fructose }} / \mathrm{M}_{\text {nitrate }}$ ratios of (a) 0 , (b) 0.1 , (c) 0.2 and (d) 0.5 .

\subsection{Composition of Residual Acid after Fe Removal}

The residual acid solution was characterised as shown in Figure 4. Without fructose, a slight decrease in nitrate concentration from $86.3 \mathrm{~g} / \mathrm{L}$ to $78.4 \mathrm{~g} / \mathrm{L}$ (Figure 4a) was obeserved due to the thermal decomposition of nitrate to $\mathrm{NO}_{2}$ and/or $\mathrm{NO}$ (Equations (1) and (2)) [15]. Moreover, the acid's pH declined from 0.3 to 0.21 (Figure $4 \mathrm{a}$ ) because $\mathrm{H}^{+}$was generated during the hydrolysis of ferric Fe 
to Fe oxyhydroxide with hematite as the final product (Equation (3)). As the hydrolysis of ferric Fe continued, $\mathrm{H}^{+}$accumulated in the residual acid, inhibiting the hydrolysis of ferric Fe (Equation (3)) and resulting in a high Fe residual (Figure 1a).

$$
\begin{aligned}
& \mathrm{NO}_{3} \rightarrow \mathrm{NO}_{2}+\mathrm{O} \\
& \mathrm{NO}_{3} \rightarrow \mathrm{NO}+\mathrm{O}_{2} \\
& 2 \mathrm{Fe}\left(\mathrm{NO}_{3}\right)_{3}+3 \mathrm{H}_{2} \mathrm{O}=\mathrm{Fe}_{2} \mathrm{O}_{3}+6 \mathrm{NO}_{3}^{-}+6 \mathrm{H}^{+}
\end{aligned}
$$

With the addtion of fructose, a steady decrease in nitrate from $39.3 \mathrm{~g} / \mathrm{L}$ to $5.8 \mathrm{~g} / \mathrm{L}$ and $0.9 \mathrm{~g} / \mathrm{L}$ was observed with an increase in molar ratio from 0.1 to 0.2 and 0.5 (Figure 4a), respectively. Nitrate is a strong oxidant that can react with fructose to produce ketogluconic, butanedioic and oxalic acids, and finally, $\mathrm{CO}_{2}$ and $\mathrm{H}_{2} \mathrm{O}$ (Equation (4)) [22]. Figure $4 \mathrm{~b}$ shows that the TOC of the acid apparently increased from $16.4 \mathrm{~g} / \mathrm{L}$ to $78.14 \mathrm{~g} / \mathrm{L}$ with an increase in molar ratio from 0.1 to 0.5 before hydrothermal reaction. After hydrothermal reaction, the residual TOC was approximately $125 \mathrm{mg} / \mathrm{L}$ within the molar ratio range of 0.2 , but it remained at $26.4 \mathrm{~g} / \mathrm{L}$ at a molar ratio of 0.5 (Figure $4 \mathrm{~b}$ ) in accordance with the overdosed fructose. Moreover, the redox reduction between nitrate and fructose was accompanied by the consumption of $\mathrm{H}^{+}$(Equation (4)). When the molar ratio varied from 0.1 to 0.2 , the acid's $\mathrm{pH}$ also increased from 0.92 to 1.46 (Figure 4a), which accelerated the hydrolysis of ferric Fe to hematite particles. When fructose was overdosed, nitrate was nearly completely consumed in the redox reaction (Equation (4)), and the acid's pH sharply increased to 3.25 (Figure 4a). Thus, fructose was oxidised incompletely to accumulate the intermediate oxalic acid in the solution. Subsequently, trivalent Fe predominated in nitric acid and was reduced by fructose to form ferrous Fe. In parallel, trivalent rare-earth elements were also reduced by the overdosed fructose [23]. A portion of oxalic acid was complexed with ferrous Fe with the generation of humboldtine precipitates. Accordingly, complexation reaction between oxalic acid and rare-earth elements also occurred [24], resulting in the precipitation of these elements. During hydrothermal treatment, unoxidised fructose was polymerised into macromolecules, e.g., aromatic compounds and oligosaccharides [25], and further nucleated to $\mathrm{C}$ spheres via the aldol condensation and dehydration route [21]. Such macromolecules, which also have plenty of hydroxyl groups and exhibit a high affinity towards chelated ferrous Fe and rare-earth elements [26], remained in the treated acid. This condition inhibited the hydrolysation of Fe into Fe oxyhydroxide. Therefore, Fe was removed inefficiently at a molar ratio of 0.5 .

$$
5 \mathrm{C}_{6} \mathrm{H}_{12} \mathrm{O}_{6}+16 \mathrm{NO}_{3}^{-}+16 \mathrm{H}^{+} \rightarrow 30 \mathrm{CO}_{2}+8 \mathrm{~N}_{2}+20 \mathrm{H}_{2}+18 \mathrm{H}_{2} \mathrm{O}
$$
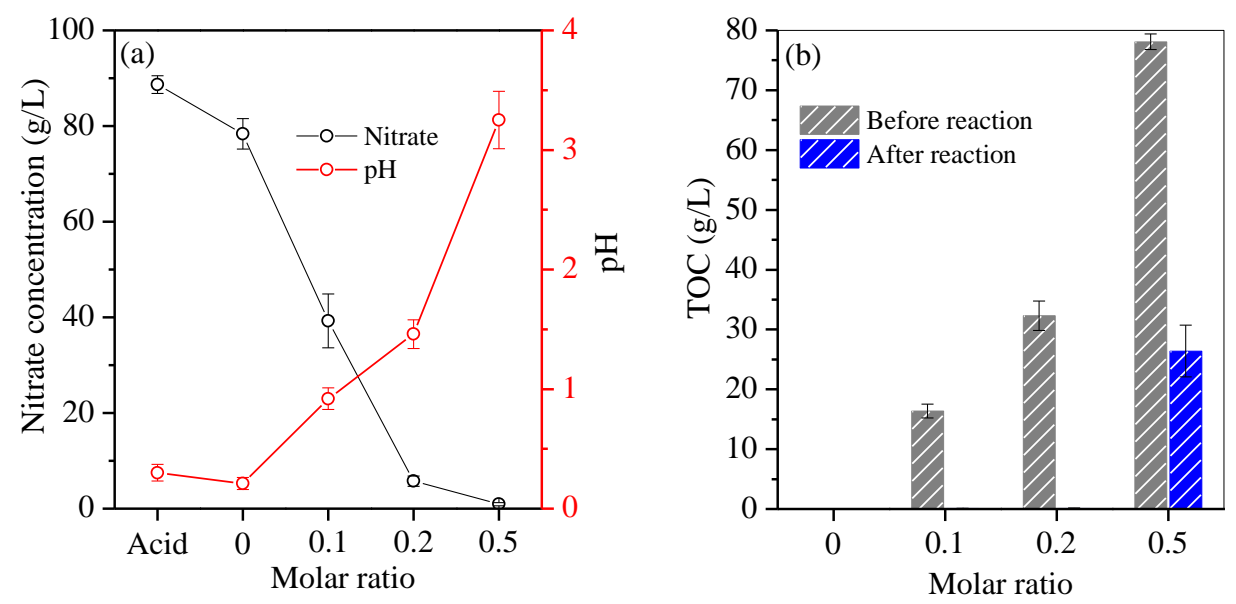

Figure 4. Variation of (a) nitrate and $\mathrm{pH}$, and (b) TOC in the hydrothermal reaction. 


\subsection{Hydrothermal Time Optimisation at the Optimal Fructose Dosage}

To optimise hydrothermal time, control experiments of Fe removal at the optimal molar ratio of 0.2 were performed. The result is presented in Figure 5. After hydrothermal treatment, Fe removal reached $1.35 \%$ for $0.25 \mathrm{~h}, 46.5 \%$ for $1 \mathrm{~h}, 98.5 \%$ for $3 \mathrm{~h}$ and nearly $100 \%$ for $6 \mathrm{~h}$ (Figures $5 \mathrm{a}$ and $1 \mathrm{a}$ ). The loss of $\mathrm{Nd}$, Pr and Dy was $0.3 \%, 0.2 \%$ and $0.2 \%$ after $0.25 \mathrm{~h}$, apparently up to $1.2 \%, 0.9 \%$ and $1.1 \%$ after $1 \mathrm{~h}$, and steadily increased to $1.7 \%, 1.7 \%$ and $1.8 \%$ after $3 \mathrm{~h}$ (Figure $5 \mathrm{~b}$ ), respectively, and kept nearly unchanged with an extended time course from $3 \mathrm{~h}$ to $6 \mathrm{~h}$ (Figure $1 \mathrm{~b}$ ).
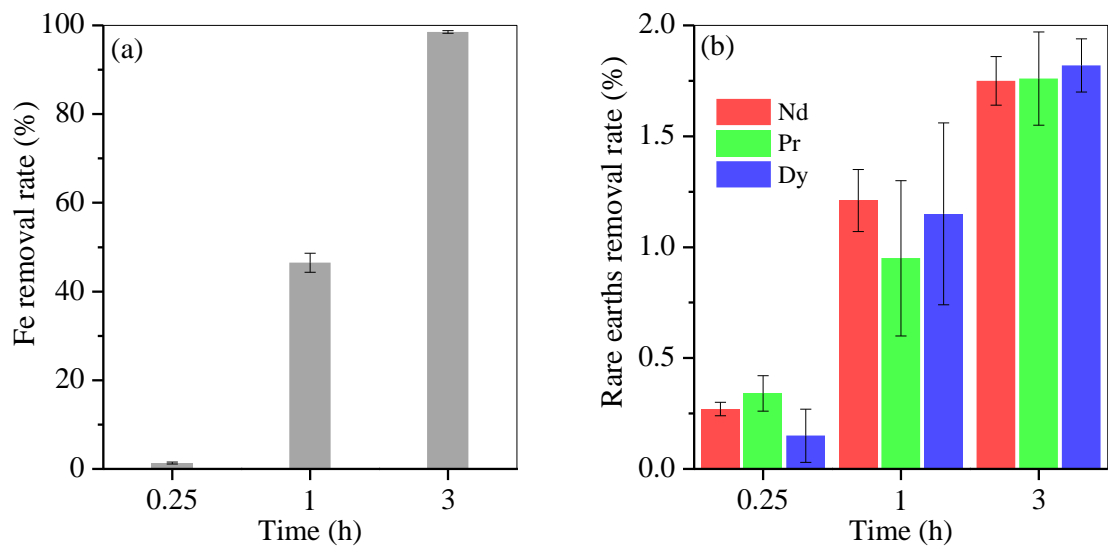

Figure 5. Time course of (a) Fe and (b) rare-earth element removal.

Fe-bearing deposits were also characterised via XRD analysis and SEM. The generated deposit was weakly crystallised FeOOH aggregates (Figures 6a and 7a) at $1 \mathrm{~h}$ and was further converted into well-crystallised hematite nanoparticles with an average diameter of $100 \mathrm{~nm}$ after $3 \mathrm{~h}$ (Figures $6 \mathrm{~b}$ and $7 \mathrm{~b})$, similar to that generated at $6 \mathrm{~h}$ (Figures 2c and 3c).

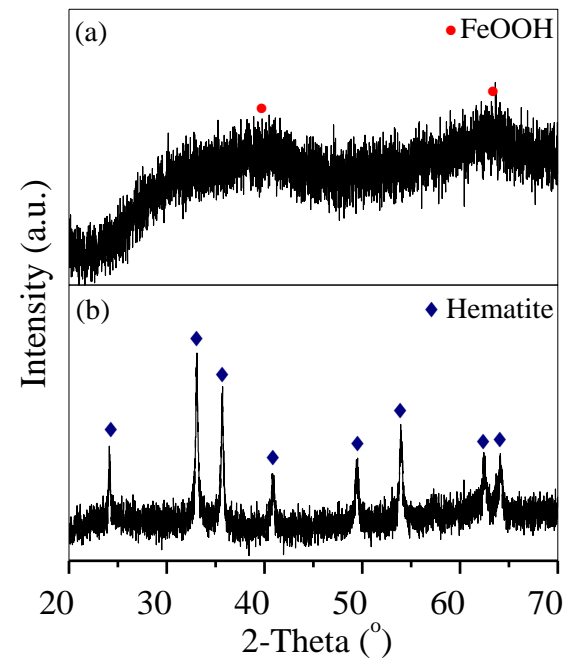

Figure 6. XRD patterns of the deposits generated at (a) $1 \mathrm{~h}$ and (b) $3 \mathrm{~h}$. 


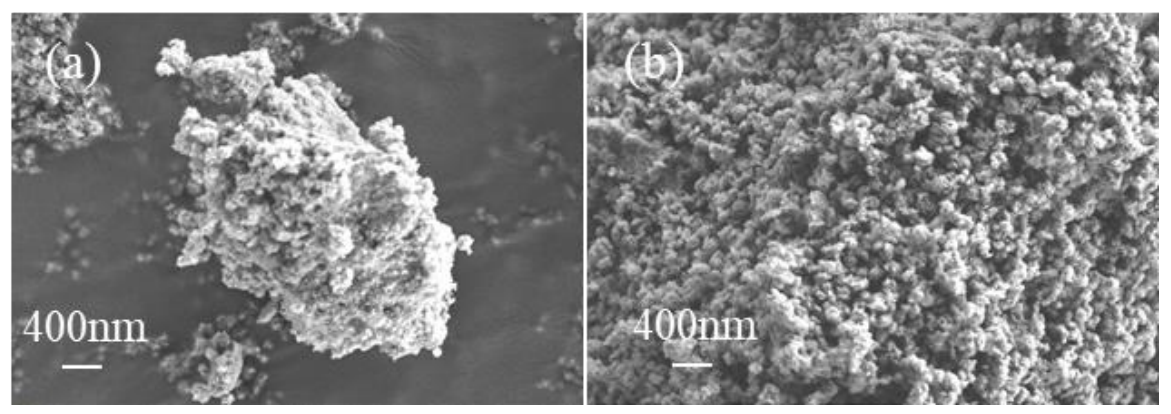

Figure 7. SEM images of the deposits generated at (a) $1 \mathrm{~h}$ and (b) $3 \mathrm{~h}$.

\subsection{Hematite Precipitation Mechanism}

Fe removal was related to an increased acid $\mathrm{pH}$ in the oxidation of fructose by nitrate. Nitrate concentration was reduced from $86.4 \mathrm{~g} / \mathrm{L}$ to $22.8 \mathrm{~g} / \mathrm{L}$ and $11.6 \mathrm{~g} / \mathrm{L}$ after treatment for $0.25,1$ and $3 \mathrm{~h}$, respectively (Figure 8 ). TOC exhibited a similar decreasing trend to nitrate, and its concentration dropped to $0.67 \mathrm{~g} / \mathrm{L}$ for $1 \mathrm{~h}$ and to $0.23 \mathrm{~g} / \mathrm{L}$ for $3 \mathrm{~h}$ (Figure 8) due to the oxidisation of fructose by nitrate. As the redox reaction continued, acid $\mathrm{pH}$ increased steadily (Figure 8), promoting the hydrolysis of ferric Fe to form the initial product $\mathrm{FeOOH}$.

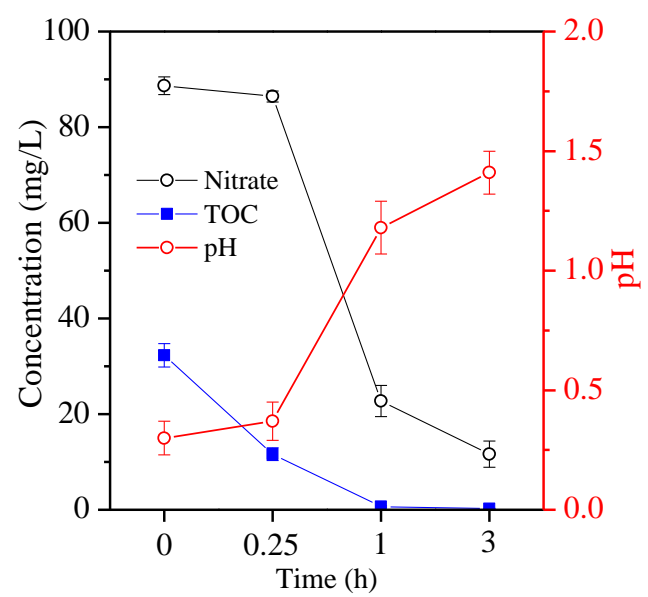

Figure 8. Variation of nitrate, TOC and $\mathrm{pH}$ with an extended time course from $0 \mathrm{~h}$ to $3 \mathrm{~h}$ of the hematite particles generated at $3 \mathrm{~h}$.

The newly generated FeOOH was weakly crystallised and had numerous hydroxyl groups for rare-earth element coordination [19,27]. However, competition adsorption occurred between $\mathrm{H}^{+}$ and the rare-earth elements on the newly formed FeOOH surface in the presence of sufficient $\mathrm{H}^{+}$, releasing rare-earth elements into the acid. Therefore, the hydroxyl group was regenerated on the newly formed FeOOH surface. Subsequently, the conjunction between two adjacent hydroxyl groups on each $\mathrm{FeOOH}$ occurred with the release of one water molecule to generate an irreversible $\mathrm{Fe}-\mathrm{O}-\mathrm{Fe}$ bond $[27,28]$. As the conjunction reaction continued, rare-earth elements were released and maintained a high concentration in the acid. In parallel, the weakly crystallised FeOOH block collapsed and then polymerised to generate fine hematite nanoparticles. These hematite nanoparticles, which were generated at a hydrothermal time of $6 \mathrm{~h}$, contained $67.92 \% \mathrm{Fe}, 0.78 \% \mathrm{Nd}, 0.34 \% \mathrm{Pr}$ and $0.14 \% \mathrm{Dy}$. The composition meets the grade for the active pharmaceutical ingredients of commercial hematite powder [29], demonstrating that the precipitated hematite nanoparticles were highly purified. 


\section{Conclusions}

Fe impurity in the acid solution of scrap was successfully separated via a one-step hydrothermal route with fructose as the auxiliary reagent. Through this method, fructose was oxidised by nitrate with the involvement of $\mathrm{H}^{+}$in the acid, steadily increasing the acid's $\mathrm{pH}$ and enhancing the hydrolysis of ferric Fe to hematite with FeOOH as the intermediate. Nearly $100 \%$ Fe was precipitated in the form of hematite nanoparticles with Fe content of $67.92 \%$ by adding fructose at a molar ratio of 0.2 . The residual $\mathrm{Fe}$ in the leaching acid was less than $10 \mathrm{mg} / \mathrm{L}$, and rare-earth element concentrations were 8.8, 2.1 and $0.4 \mathrm{~g} / \mathrm{L}$ for $\mathrm{Nd}$, Pr and Dy, respectively. Conversely, only $81.8 \%$ of the total Fe was removed as irregular hematite aggregates without fructose, and residual Fe was approximately $1.9 \mathrm{~g} / \mathrm{L}$.

This method exhibits two advantages in the recycling of rare-earth elements from scrap. Firstly, Fe is effectively separated from the leaching acid of scrap to generate high-purity hematite nanoparticles. Secondly, low residual Fe and high concentrations of rare-earth elements are produced in the residual acid. Therefore, highly purified rare-earth products can be economically recycled due to the low Fe content caused by repeatedly using an extraction reagent.

Author Contributions: Conceptualization, S.Z. and Y.L.; methodology, S.Z.; software, T.S.; validation, Y.C., Y.L. and S.Z.; formal analysis, T.S.; investigation, Z.Q.; resources, M.H.; data curation, X.L.; writing-original draft preparation, S.Z.; writing-review and editing, Y.L.; visualization, T.S.; supervision, Y.C.; project administration, S.Z.; funding acquisition, M.H. All authors have read and agreed to the published version of the manuscript.

Funding: This research was funded by National Natural Science Foundation of China, grant number 51578118, 51908109, 51878133 and 51878134 and the Science and Technology Program of Jilin Province grant number 20190303001SF.

Conflicts of Interest: The authors declare no conflict of interest.

\section{References}

1. Firdaus, M.; Rhamdhani, M.A.; Durandet, Y.; Rankin, W.J.; McGregor, K. Review of high-temperature recovery of rare earth (Nd/Dy) from magnet waste. J. Sustain. Metall. 2016, 2, 276-295. [CrossRef]

2. Önal, M.A.R.; Borra, C.R.; Guo, M.; Blanpain, B.; Van Gerven, T. Recycling of NdFeB Magnets Using Sulfation, Selective Roasting, and Water Leaching. J. Sustain. Metall. 2015, 1, 199-215. [CrossRef]

3. Yang, Y.; Walton, A.; Sheridan, R.; Güth, K.; Gauß, R.; Gutfleisch, O.; Buchert, M.; Steenari, B.-M.; Van Gerven, T.; Jones, P.T.; et al. REE Recovery from End-of-Life NdFeB Permanent Magnet Scrap: A Critical Review. J. Sustain. Metall. 2017, 3, 122-149. [CrossRef]

4. Önal, M.A.R.; Borra, C.R.; Guo, M.; Blanpain, B.; Van Gerven, T. Hydrometallurgical recycling of NdFeB magnets: Complete leaching, iron removal and electrolysis. J. Rare Earths 2017, 35, 574-584. [CrossRef]

5. Yang, F.; Deng, Z.; Wei, C.; Li, C.-X.; Li, X.-B. Iron-removal by hematite from leaching liquor of high iron sphalerite. Chin. J. Nonferrous Met. 2014, 24, 2387-2392.

6. Lee, C.-H.; Chen, Y.-J.; Liao, C.-H.; Popuri, S.R.; Tsai, S.-L.; Hung, C.-E. Selective leaching process for neodymium recovery from scrap Nd-Fe-B magnet. Metall. Mater. Trans. A 2013, 44, 5825-5833. [CrossRef]

7. Zhou, H.; Wang, Y.; Guo, X.; Dong, Y.; Su, X.; Sun, X. The recovery of rare earth by a novel extraction and precipitation strategy using functional ionic liquids. J. Mol. Liq. 2018, 254, 414-420. [CrossRef]

8. Parhi, P.; Sethy, T.; Rout, P.; Sarangi, K. Separation and recovery of neodymium and praseodymium from permanent magnet scrap through the hydrometallurgical route. Sep. Sci. Technol. 2016, 51, 2232-2241. [CrossRef]

9. Matsumiya, M.; Kikuchi, Y.; Yamada, T.; Kawakami, S. Extraction of rare earth ions by tri-n-butylphosphate/phosphonium ionic liquids and the feasibility of recovery by direct electrodeposition. Sep. Purif. Technol. 2014, 130, 91-101. [CrossRef]

10. Ponou, J.; Garrouste, M.; Dodbiba, G.; Fujita, T.; Ahn, J.-W. Sulfation-Roasting-Leaching-Precipitation Processes for Selective Recovery of Erbium from Bottom Ash. Sustainability 2019, 11, 3461. [CrossRef]

11. Jianmin, Z. Ferrihydrite: Surface structure and its effects on phase transformation. Clay. Clay. Miner. 1994, 42, 737-746. [CrossRef] 
12. Qu, Z.; Wu, Y.; Zhu, S.; Yu, Y.; Huo, M.; Zhang, L.; Yang, J.; Bian, D.; Wang, Y. Green Synthesis of Magnetic Adsorbent Using Groundwater Treatment Sludge for Tetracycline Adsorption. Engineering 2019, 5, 880-887. [CrossRef]

13. Sun, M.; Yan, L.; Zhang, L.; Song, L.; Guo, J.; Zhang, H. New insights into the rapid formation of initial membrane fouling after in-situ cleaning in a membrane bioreactor. Process Biochem. 2019, 78, 108-113. [CrossRef]

14. Pavón, S.; Fortuny, A.; Coll, M.; Sastre, A. Neodymium recovery from NdFeB magnet wastes using Primene 81R. Cyanex 572 IL by solvent extraction. J. Environ. Manag. 2018, 222, 359-367. [CrossRef]

15. Wieczorek-Ciurowa, K.; Kozak, A. The thermal decomposition of $\mathrm{Fe}\left(\mathrm{NO}_{3}\right)_{3} \cdot 9 \mathrm{H}_{2} \mathrm{O}$. J. Therm. Anal. Calorim. 1999, 58, 647-651. [CrossRef]

16. Zhang, H.; Sun, M.; Song, L.; Guo, J.; Zhang, L. Fate of $\mathrm{NaClO}$ and membrane foulants during in-situ cleaning of membrane bioreactors: Combined effect on thermodynamic properties of sludge. Biochem. Eng. J. 2019, 147, 146-152. [CrossRef]

17. Zhu, S.; Fang, S.; Huo, M.; Yu, Y.; Chen, Y.; Yang, X.; Geng, Z.; Wang, Y.; Bian, D.; Huo, H. A novel conversion of the groundwater treatment sludge to magnetic particles for the adsorption of methylene blue. J. Hazard. Mater. 2015, 292, 173-179. [CrossRef]

18. Geng, Z.; Yu, Y.; Zhu, S.; Yu, H.; Liu, J.; Bian, D.; Yang, X.; Huo, H.; Huo, M. Comparing polyethersulfone and polyurethane-immobilized cells of Comamonas testosteroni QYY in treatment of an accidental dye wastewater. Chem. Res. Chin. Univ. 2017, 33, 36-43. [CrossRef]

19. Zhu, S.; Lin, X.; Dong, G.; Yu, Y.; Yu, H.; Bian, D.; Zhang, L.; Yang, J.; Wang, X.; Huo, M. Valorization of manganese-containing groundwater treatment sludge by preparing magnetic adsorbent for $\mathrm{Cu}(\mathrm{II})$ adsorption. J. Environ. Manag. 2019, 236, 446-454. [CrossRef]

20. Sandroni, V.; Smith, C.M.M. Microwave digestion of sludge, soil and sediment samples for metal analysis by inductively coupled plasma-atomic emission spectrometry. Anal. Chim. Acta 2002, 468, 335-344. [CrossRef]

21. Liu, S.; Jian, S.; Huang, Z. Carbon spheres/activated carbon composite materials with high Cr(VI) adsorption capacity prepared by a hydrothermal method. J. Hazard. Mater. 2010, 173, 377-383. [CrossRef] [PubMed]

22. Heinen, A.W.; Peters, J.A.; van Bekkum, H. The oxidation of fructose on Pt/C catalysts. the formation of d-threo-hexo-2,5-diulose and the effect of additives. Carbohydr. Res. 1997, 304, 155-164. [CrossRef]

23. Sheng, Q.; Shen, Y.; Zhang, H.; Zheng, J. Neodymium (III) hexacyanoferrate (II) nanoparticles induced by enzymatic reaction and their use in biosensing of glucose. Electrochim. Acta 2008, 53, 4687-4692. [CrossRef]

24. Vander Hoogerstraete, T.; Blanpain, B.; Van Gerven, T.; Binnemans, K. From NdFeB magnets towards the rare-earth oxides: A recycling process consuming only oxalic acid. RSC Adv. 2014, 4, 64099-64111. [CrossRef]

25. Min, L.; Wei, L.; Liu, S. Control of the morphology and chemical properties of carbon spheres prepared from glucose by a hydrothermal method. J. Mater. Res. 2012, 27, 1117-1123.

26. Delgado-Andrade, C.; Seiquer, I.; Nieto, R.; Navarro, M.P. Effects of heated glucose-lysine and glucose-methionine model-systems on mineral solubility. Food Chem. 2004, 87, 329-337. [CrossRef]

27. Qu, Z.; Dong, G.; Zhu, S.; Yu, Y.; Huo, M.; Xu, K.; Liu, M. Recycling of groundwater treatment sludge to prepare nano-rod erdite particles for tetracycline adsorption. J. Clean. Prod. 2020, 257, 120462. [CrossRef]

28. Qu, Z.; Su, T.; Chen, Y.; Lin, X.; Yu, Y.; Zhu, S.; Xie, X.; Huo, M. Effective enrichment of Zn from smelting wastewater via an integrated Fe coagulation and hematite precipitation method. Front. Environ. Sci. Eng. 2019, 13, 94. [CrossRef]

29. Fouad, N.E.; Ismail, H.M.; Zaki, M.I. Recovery of red iron oxide pigmentary powders from chemically-modified steel-pickling chemical waste. J. Mater. Sci. Lett. 1998, 17, 27-29. [CrossRef]

(C) 2020 by the authors. Licensee MDPI, Basel, Switzerland. This article is an open access article distributed under the terms and conditions of the Creative Commons Attribution (CC BY) license (http://creativecommons.org/licenses/by/4.0/). 